example, a set of wire wheels that adds nothing to the efficiency of the vehicle.

Now that $80 \%$ of our total passenger transport is by road is our Government less sensitive to the welfare of its people ?-I am, etc.,

WILliAM
Road Injuries Research Group,
The Birmingham Accident Hospital, Birmingham 15.

\section{Collaborating Disciplines}

SIR,-The article by Dr. John T. Scales (21 August, p. 470) is a fine review of the present trends in biological engineering and medicine, a trend made necessary by the extreme degree of specialization in all fields of endeavour and the paradoxical need for the integration of diverse scientific interests.

Another aspect of collaboration should be mentioned, because it is one in which Dr. Scales himself has played no small part. I refer to the evolution of the many-sided efforts during the past 20 years under the auspices of the British Standards Institution. The extraordinary variety and the multitude of products affecting medical and hospital practice which have been studied and standardized by groups representing industry, science, and medicine have doubtless played a part in advancing the sort of collaboration which Dr. Scales describes. Medical men have devoted much time to this work, the results of which should be better recognized by their colleagues.

Too often in the past surgeons have been temperamental in insisting upon the use of peculiar and untested materials or devices. Even now they may permit themselves, like other doctors, to be over-impressed by modern salesmanship. To-day, British Standards ensure the availability of reliable equipment because of the collaboration which has gone into its production. In one field-surgical implants-the weak link in supply may sometimes be in the failure of hospital supply officers to recognize the importance of these standards and to ensure not only that they are available but that inferior products from old stocks are not mixed with them.

In the broader field that Dr. Scales describes there are two great needs. The first is a national advisory institute for the examination, experimentation, clinical study, and approval of new designs of equipment, instruments, and materials. The second is a lexicon of terms-for an example see editorial "Surgical Implants"; f. Bone ft Surg., Vol. 47B, February 1965-for the illumination of engineers and biologists: the technical language of each group is difficult for the other.-I am, etc.,

Exeter.

Norman Capener.

\section{Subdural “ Haematoma” in Infancy}

SIR,-I am sorry that Dr. Patricia A. Russell in her interesting paper "Subdural Haematoma in Infancy" (21 August, p. 446) uses the term haematoma, which although widely accepted in this context appears to me to be inaccurate. The nature of the subdural fluid is not described by Dr. Russell in detail, but (unless the series differs greatly from others that have been published) was probably in most cases clear and xantho- chromic and containing much protein. In 97 cases seen in this department in the last six years only 12 had blood in the subdural fluid. The term haematoma seems not to be justified, although in many cases the initial lesion may have been a blood clot. There are so many unexplained aspects of this condition or group of conditions that I suggest the term effusion should be used when blood is not present. For example, it is known that subdural fluid collection is an infrequent complication in meningitis in the absence of trauma. Again, subdural fluid (not blood) is occasionally found a few days after birth, when it is hard to believe that a blood clot was the precursor. Unexplained also are the cases where the whole cerebrum is enveloped in subdural fluid perhaps several hundred millilitres in volume. Is it possible that a haematoma so large existed previously and yet the baby lived ?

The avoidance of the term haematoma has, however, some practical importance. Its use may partly explain two misconceptions which are commonly encountered. (1) When inserting a needle beneath the dural space for diagnostic purposes the doctor unfamiliar with the condition may expect to aspirate blood. If a few millilitres are obtained the diagnosis is considered as established, even when the history of illness is so many weeks that a haematoma would long before have changed from being pure blood. (2) When yellow fluid is obtained (as is more commonly the case) any blood it contains is regarded as a natural occurrence, whereas its presence is the direct result of damage to vessels when inserting the needle.

For these and other reasons therefore I hope that the term subdural haematoma may be reserved for those cases where a collection of blood is found in the subdural space.-I am, etc.,

\section{The Hospital for Sick Children,}

KENNETH Till.

London W.C.1.

\section{Reactions to Nalidixic Acid}

SIR,-Early in 1965 the Committee on Safety of Drugs asked doctors to report any rashes or disturbances of the central nervous system occurring in patients who were taking nalidixic acid ("Negram"). The reports received following this request appear to confirm the first impressions that, though there seems no reasonable doubt that a causal relationship exists between the use of the drug and such reactions, the latter are transient and reversible.

It is the view of the Committee that the fear of producing these reactions in some patients need not, in the present state of knowledge, deter doctors from prescribing this drug when it is positively indicated. Nevertheless, since some of the effects may be alarming to patients, doctors might care to warn them of their possible occurrence.

When the reactions affect the nervous system they usually occur within half an hour of taking the drug and persist for two or three hours. Sometimes, however, they are first experienced after the second or third dose and increase in severity with subsequent doses. Visual disturbances, excitement, depression, confusion, and hallucinations have been reported. Headache, giddiness, drowsiness, syncope, and sensory disturbances have also occurred in a few instances. Onepatient had a grand mal attack which might have been due to the drug.

The exact incidence of reactions is difficult to assess, but between May 1964 and April 1965 there were reported to the Committee 52 cases of skin rashes and 126 cases of reactions affecting the nervous system in patients being treated with nalidixic acid. Between January 1964 and February 1965 general practitioners alone issued approximately 77,000 prescriptions for the drug.

The Committee would like to thank doctors. for their help and to acknowledge the cooperation of the manufacturers in the inquiry. -I am, etc.,

D. A. CAHAL,
Medical Assessor.
Committee on Safety of Drugs,
Queen Anne's Mansions,
Queen Anne's Gate,
London S.W.1.

\section{Hyperbaric Oxygenation}

SIR,-Your leading article on hyperbaric oxygenation (14 August, p. 377) succinctly summarizes the present position.

Those of us working in this field with small one-man chambers ${ }^{1}$ would, however, challenge your statement that larger chambers in which attendants can also be present are needed for most types of treatment other than radiotherapy.

In this unit we have been successfully treating very ill patients for gas gangrene and carbon monoxide poisoning, as well as those with chronic osteomyelitis and certain ischaemic lesions of the lower limb. In the immediate post-operative period, also, patients will accept treatment so that ischaemic skin flaps may be resuscitated and skin grafts sustained. We have found the equipment easy to use, and nurses can be trained in a few hours to pressurize patients and attend them during treatment.

Hyperbaric oxygen therapy thus becomes a practical proposition in centres where the cost of large chambers will inevitably make their use impossible.-I am, etc.,

$$
\begin{aligned}
& \text { Queen Mary's Hospital, } \\
& \text { Roehampton, } \\
& \text { London S.W.15. } \\
& \text { Reference } \\
& \text { Williams, K. G., and Hopkinson, W. I., Pro- } \\
& \text { ceedings of Second International Congress on } \\
& \text { Hyperbaric Oxygenation, edited by I. Leding- } \\
& \text { ham, 1965, p. } 373 \text {. Livingstone, London. }
\end{aligned}
$$

\section{Unsuspected Deafness in an Immigrant} Child

SIR,-The difficulty in communication. with members of a community of different language may present a great problem in the diagnosis of medical disorders. This is particularly so in the case of deafness.

A Turkish Cypriot schoolgirl aged 8 years was seen at a school medical inspection in April 1964. The mother could not speak English and did not attend the interview. The child was vivacious and co-operative, with an alert and intelligent facial expression. When spoken to slowly, in simple language, she responded by making a vocal noise, and by nodding or shaking her head. She did not appear to articulate sounds, and her voice quality was abnormal in nasality and intensity. Both the headmistress and her own teacher, who were 